\title{
Effect of lamb age, breed and sex on plasma LH after administration of $\mathrm{GnRH}$
}

\author{
J. P. Hanrahan, J. F. Quirke and J. P. Gosling* \\ The Agricultural Institute, Belclare, Tuam, Co. Galway, and *Department of Biochemistry, \\ University College, Galway, Ireland
}

\begin{abstract}
Summary. Male lambs of the Finn, Fingalway and High Fertility breeds aged 4 or 8 weeks of age were injected i.m. with $5,10,50$, or $100 \mu \mathrm{g} \mathrm{GnRH}$. Plasma $\mathrm{LH}$ after GnRH injection increased with age and GnRH dose but there was no effect of breed. There was no interaction among the three factors studied. In a second experiment the response of male and female lambs, aged 8 weeks, to $100 \mu \mathrm{g} \mathrm{GnRH}$ was investigated for 5 genetic groups (Finn, Galway Control, Galway Elite, Fingalway and High Fertility). Breed differences in plasma LH of male lambs were not found, which agreed with the result of the first experiment. Breed differences were observed for females, with the lowest values being observed for Finn and High Fertility lambs which represent the two most prolific breeds. This finding suggested breed differences in the development of the hypothalamic-pituitary-ovarian circuit. The difference between Galway Control and Galway Elite lambs was not significant $(P>0 \cdot 10)$.
\end{abstract}

\section{Introduction}

Breed and strain differences in plasma $\mathbf{L H}$ have been reported for young lambs (Thimonier, Pelletier \& Land, 1973; Bindon, 1973; Carr \& Land, 1975; Hanrahan, Quirke \& Gosling, 1977) and these differences have been associated with genetic differences in female fecundity. Plasma LH levels, however, are extremely variable, both among animals and among sequential samples from the same animal, due to the episodic nature of LH release from the pituitary (Foster, Jaffe \& Niswender, 1975). The administration of GnRH will induce a discharge of LH in lambs (Bindon, Ch'ang \& Evans, 1974) and measurement of this response may yield a more precise estimator of differences among individuals in LH status. If the response to GnRH is related to fecundity (litter size) then the use of $\mathrm{LH}$ as an aid to (genetic) selection for increased fecundity will be facilitated. A problem with such an approach is the possibility of interactions between genotype and $\mathrm{GnRH}$ dose.

The usefulness of GnRH in selection programmes has been explored in the present work by using young lambs from different genetic backgrounds to examine the effects of age, sex and GnRH dose on plasma LH after treatment with GnRH.

\section{Materials and Methods}

Breeds

Experimental animals were taken from the Finn, Fingalway, High Fertility, Galway Elite and Galway Control genetic groups maintained within our Institute. The mean litter size for mature ewes of these groups is $2 \cdot 5,2 \cdot 0,2 \cdot 0,1 \cdot 5$ and 1.4 , respectively (Hanrahan et al., 1977): 


\section{Experiment 1}

This experiment was designed to explore the importance of $\mathrm{GnRH}$ dose in studying the plasma $\mathrm{LH}$ response to $\mathrm{GnRH}$. March-born male lambs were studied at 4 or 8 weeks of age and 4 doses of $\mathrm{GnRH}(5,10,50$ and $100 \mu \mathrm{g}$ in $2 \mathrm{ml}$ sterile water) were used at each age. A total of 16 lambs from each of the Finn, Fingalway and High Fertility breeds were used, with 2 individuals from each breed per age $\times \mathrm{GnRH}$ dose subclass. Blood samples were collected at 15 , $30,60,90$ and 120 min after intramuscular injection of the GnRH.

\section{Experiment 2}

The lambs in this experiment were 8 weeks of age and were the progeny of within-breed matings of Finn, Galway Control, Galway Elite, Fingalway and High Fertility ewes; they were actually a subset of the lambs used at 8 weeks of age in a previous study of plasma LH (Hanrahan et al., 1977). In selecting the subset of animals for the present experiment only one offspring per ewe was chosen and the sexes were balanced as far as possible. The distribution of the number of lambs by breed and sex is given in Table 3. The lambs were injected with $100 \mu \mathrm{g}$ $\mathrm{GnRH}$ (in $2 \mathrm{ml}$ sterile water) and 8 samples were then taken at 15-min intervals, and another 4 samples at 30 -min intervals.

Assay

Blood samples were taken from a jugular vein into evacuated tubes containing EDTA. All samples were placed immediately in an ice-bath and allowed to cool before centrifugation. The plasma was then removed and stored at $-20^{\circ} \mathrm{C}$ until assayed. The plasma $\mathrm{LH}$ values were assayed in duplicate (Exp. 1) or triplicate (Exp. 2) by a double-antibody radioimmunoassay using LER 1374A for iodination and NIH-LH-S18 as standard (Hanrahan et al., 1977). The antiserum was rabbit anti-ovine LH, DBS3/5, kindly supplied by Dr G. Jenkin.

The samples from Exp. 2 were assayed before those from Exp. 1 and different quality control plasma pools and procedures were used. The sensitivity, as calculated from the error in the amount of label bound at zero standard and the slope for each assay run, was $1 \mathrm{ng} / \mathrm{ml}$ or lower. For Exp. 2 samples, with control plasma LH averaging $41.7 \mathrm{ng} / \mathrm{ml}$, the within- and between-assay coefficients of variation were $17 \cdot 1 \%$ and $18 \cdot 1 \%$, respectively (15 assays). For Exp. 1 samples, the control plasma contained $55.4 \mathrm{ng} / \mathrm{ml}$ and the within- and between-assay coefficients of variation were $7 \cdot 1 \%$ and $13.9 \%$, respectively ( 3 assays). In two of these assays $20,50,100,200 \mu \mathrm{l}$ aliquots of control plasma (made up to the standard assay volume) were measured: the LH concentrations were closely related to the volume of control plasma used (correlation coefficient of $0.997 ; P<0.01$; d.f. $=6$ ).

Samples from Exp. 1 were processed in three assays: the first and second contained all samples from 4- and 8-week-old lambs, respectively. The third combined the 15- and 30-min samples from both 4- and 8-week-old lambs to give an estimate of age effects unbiased by any inter-assay variation. In Exp. 2 samples were measured in a total of 15 assays with all samples from an individual animal included in the same assay. At least two of the breeds being studied were included in each assay so that confounding of assay effects with breed difference was avoided.

\section{Statistical analysis}

Replicate determinations were averaged and as well as analysing the values for each 
sampling time certain summary values were derived for each individual. In Exp. 1 the derived variables were:

Total-LH = area under the curve which joins the values at each time period; and

Slope- $\mathrm{LH}=$ linear regression coefficient of log plasma LH on time.

In Exp. 2 Total-LH was calculated and in addition the following were obtained:

4S-LH = mean of the first four samples after injection; and

Peak-LH $=$ highest sample value.

Least squares procedures were used and the models employed contained all pertinent main effects (breed, sex, age, GnRH dose) as well as two-factor interactions. In the analysis of variance the effects of $\mathrm{GnRH}$ dose were partitioned into a linear component, which measures the significance of the linear change in response per unit change in GnRH dose, and a non-linear component, which reflects the significance of the departure from linearity of the relationship between response and GnRH dose. Because of the relationship between mean and variance all LH data were transformed to the logarithmic (base 10) scale before analysis.

The effect of GnRH on the variation among animals in plasma LH was assessed by comparing the coefficients of variation for $4 \mathrm{~S}-\mathrm{LH}$ and basal $\mathrm{LH}$ levels averaged over 4 samples taken at 15-min intervals before GnRH injection (Hanrahan et al., 1977).

\section{Experiment 1}

\section{Results}

The results of this experiment were first analysed separately for 4- and 8-week-old lambs. These analyses revealed no evidence of any breed $x$ dose interaction. Consequently the effect of GnRH dose, averaged over breeds, on plasma LH is shown in Text-fig. 1 while overall breed

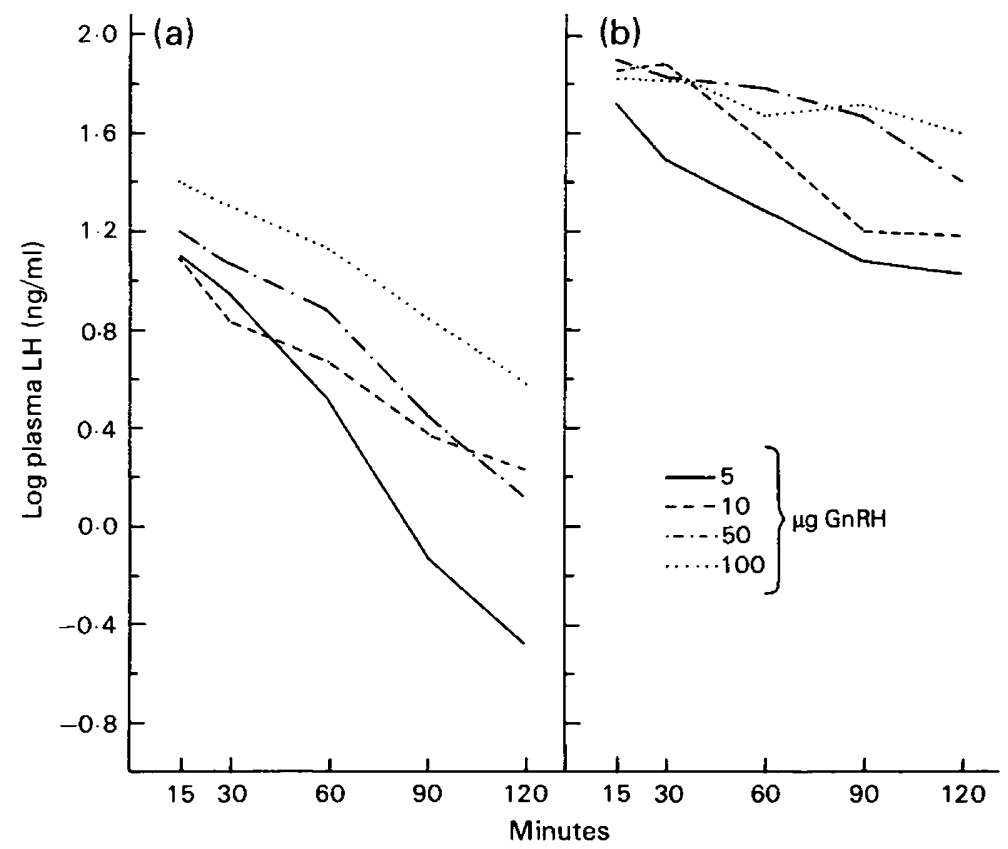

Text-fig. 1. The effect of GnRH dose on plasma LH levels at 15, 30, 60, 90 and 120 min after injection in (a) 4-week-old male lambs and (b) 8-week-old male lambs. There were 6 lambs for each $\mathrm{GnRH}$ dose at each age. 
means are given in Text-fig. 2. Breed effects on plasma LH were not significant at any sampling time while the effects of GnRH dose were significant at all sampling times except at 15 min after injection (Table 1). The nature of the GnRH dose effect depended on the age of the lamb since the linear component of dose adequately explained the pattern at 4 weeks of age but the deviations from linearity were significant at $30 \mathrm{~min}$ and $60 \mathrm{~min}$ in 8-week-old lambs (Table 1). This age difference is reflected in the analysis of the effects of GnRH dose on Total-LH (Table 1).

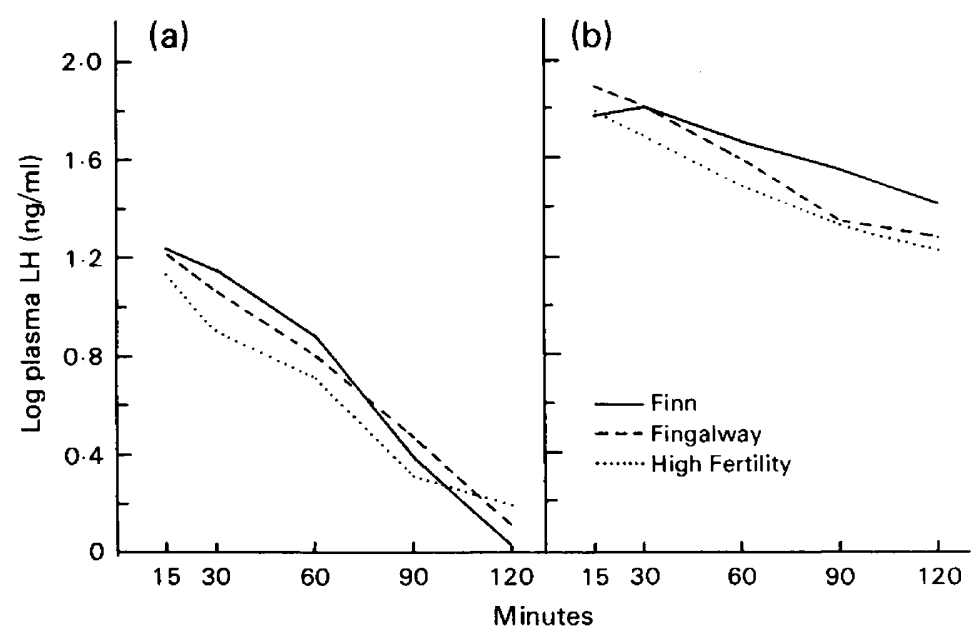

Text-fig. 2. Breed differences in the effect of GnRH on plasma $\mathbf{L H}$ at 15, 30, 60, 90 and 120 min after injection in (a) 4-week-old male lambs, and (b) 8-week-old male lambs. Each breed was represented by 8 lambs at each age.

Table 1. F-ratios for the linear and non-linear effects of GnRH dose on log plasma LH in lambs of different ages

\begin{tabular}{|c|c|c|c|c|}
\hline \multirow{2}{*}{$\begin{array}{c}\text { Sampling } \\
\text { time } \\
\text { (min) }\end{array}$} & \multicolumn{2}{|c|}{4 weeks } & \multicolumn{2}{|c|}{8 weeks } \\
\hline & Linear & Non-linear & Linear & Non-linear \\
\hline 15 & $3 \cdot 15$ & 0.04 & 0.71 & 2.92 \\
\hline 30 & $5 \cdot 36^{*}$ & 0.24 & $6 \cdot 30^{*}$ & $17 \cdot 51^{* *}$ \\
\hline 60 & $8.66^{*}$ & 0.16 & $11.93^{* *}$ & $8 \cdot 55^{* *}$ \\
\hline 90 & $7 \cdot 37^{*}$ & 1.09 & $21.38^{* *}$ & 2.42 \\
\hline 120 & $6 \cdot 13^{*}$ & 1.97 & $6.95^{*}$ & 0.22 \\
\hline Total-LH & $7.53^{*}$ & 0.24 & $14 \cdot 35^{* *}$ & $6.81^{*}$ \\
\hline
\end{tabular}

Least squares means and the results of F-tests of the main effects are given in Table 2 for Total-LH and Slope-LH and for 15-min and 30-min plasma LH levels determined in a single assay for 4- and 8-week-old lambs. Age had a significant effect on all variables with a substantial increase in response from 4 to 8 weeks. The linear component of the GnRH dose effect was significant for all variables except $15 \mathrm{~min}$ LH. The interactions of breed $\times$ age, breed $\times \mathrm{GnRH}$ dose and age $\times \mathrm{GnRH}$ dose all failed to reach statistical significance $(P>0 \cdot 20)$.

The pooled within subclass correlations between plasma LH determinations in repeated assays were 0.93 and 0.95 for $15-\mathrm{min}$ and $30-\mathrm{min} \mathrm{LH}$, respectively. 
Table 2. Least squares means (log scale), standard errors (s.e.m.) and tests of significance (F-ratio $\dagger$ ) for the effects of age and breed on the response of lambs to different $\mathrm{GnRH}$ doses

\begin{tabular}{llcccc}
\hline Factor & & Total-LH & Slope-LH $\ddagger$ & 15 -min LH & 30 -min LH \\
\hline GnRH & $5 \mu \mathrm{g}$ & 2.42 & -1.30 & 1.36 & 1.26 \\
& $10 \mu \mathrm{g}$ & 2.59 & -0.79 & 1.44 & 1.32 \\
& $50 \mu \mathrm{g}$ & 2.71 & -0.81 & 1.53 & 1.42 \\
& $100 \mu \mathrm{g}$ & 2.81 & -0.50 & 1.53 & 1.48 \\
& s.e.m. & 0.07 & 0.16 & 0.07 & 0.07 \\
& F-ratio & $15.18^{* *}$ & $8.52^{* *}$ & 2.96 & $5.66^{*}$ \\
& (linear) 8 & & & & \\
\hline Age & 4 weeks & 1.75 & -1.17 & 1.31 & 1.16 \\
& 8 weeks & 2.51 & -0.53 & 1.62 & 1.58 \\
& s.e.m. & 0.05 & 0.11 & 0.05 & 0.05 \\
& F-ratio & $126.55^{* *}$ & $16.74^{* *}$ & $22.01^{* *}$ & $36.97^{* *}$ \\
\hline Breed & Finn & 2.68 & -0.84 & 1.50 & 1.42 \\
& Fingalway & 2.64 & -0.80 & 1.49 & 1.40 \\
& High Fertility & 2.58 & -0.91 & 1.42 & 1.28 \\
& s.e.m. & 0.06 & 0.14 & 0.06 & 0.06 \\
& F-ratio & 0.75 & 0.19 & 0.55 & 1.59 \\
\hline
\end{tabular}

$* P<0.05,{ }^{* *} P<0.01$.

$\dagger$ The error mean square was associated with 30 d.f. for all F-tests.

$\ddagger(\log (\mathrm{ng} / \mathrm{ml})$ per $\mathrm{min}) \times 100$.

$\S \mathrm{F}$-ratio for the linear regression on $\mathrm{GnRH}$ dose.

\section{Experiment 2}

Analysis of variance revealed a significant breed $x$ sex interaction for Total-LH, 4S-LH and Peak-LH. The inter-correlations of these three variables were all greater than 0.93 . Table 3 shows the least squares means by breed $x$ sex subclass for all three variables. The least squares means for each sampling time (Text-fig. 3) show that the Finn and High Fertility females had consistently lower $\mathrm{LH}$ values than their male counterparts at all sampling times, Fingalway females had lower values initially but at $2 \mathrm{~h}$ after injection the rankings of the sexes had changed and there was little difference between the sexes for either Galway group. The source of the interaction was therefore a clear sex difference for the Finn and High Fertility lambs with no evident sex differences in the two Galway groups. Another way of summarizing the results in

Table 3. Least squares means ( \pm s.e.m.) showing the effects of breed and sex on plasma LH after administration of $\mathrm{GnRH}$

\begin{tabular}{llccccc}
\hline & & \multicolumn{5}{c}{ Breed } \\
\cline { 3 - 7 } $\begin{array}{c}\text { Trait } \\
\text { (log scale) }\end{array}$ & Sex & Finn & Fingalway & Fertility & $\begin{array}{c}\text { Galway } \\
\text { Elite }\end{array}$ & $\begin{array}{c}\text { Galway } \\
\text { Control }\end{array}$ \\
\hline Total-LH & Male & $\begin{array}{c}2.58 \pm 0.09 \\
(5)\end{array}$ & $\begin{array}{c}2.59 \pm 0.11 \\
(3)\end{array}$ & $\begin{array}{c}2.67 \pm 0.12 \\
(3)\end{array}$ & $\begin{array}{c}2.59 \pm 0.10 \\
(4)\end{array}$ & $\begin{array}{c}2.39 \pm 0.12 \\
(3)\end{array}$ \\
& Female & $2.28 \pm 0.09$ & $2.49 \pm 0.08$ & $2 \cdot 10 \pm 0.12$ & $2.61 \pm 0.09$ & $\begin{array}{c}2.46 \pm 0.09 \\
(5)\end{array}$ \\
\hline Peak-LH & Male & $1.77 \pm 0.09$ & $1.88 \pm 0.12$ & $1.78 \pm 0.12$ & $1.74 \pm 0.10$ & $1.56 \pm 0.12$ \\
& Female & $1.50 \pm 0.09$ & $1.71 \pm 0.08$ & $1.34 \pm 0.12$ & $1.77 \pm 0.09$ & $1.72 \pm 0.09$ \\
\hline 4S-LH & Male & $1.69 \pm 0.08$ & $1.75 \pm 0.11$ & $1.72 \pm 0.11$ & $1.62 \pm 0.09$ & $1.45 \pm 0.11$ \\
& Female & $1.35 \pm 0.09$ & $1.54 \pm 0.08$ & $1.25 \pm 0.11$ & $1.67 \pm 0.09$ & $1.57 \pm 0.09$ \\
\hline
\end{tabular}

Values in parentheses indicate the no. of lambs. 


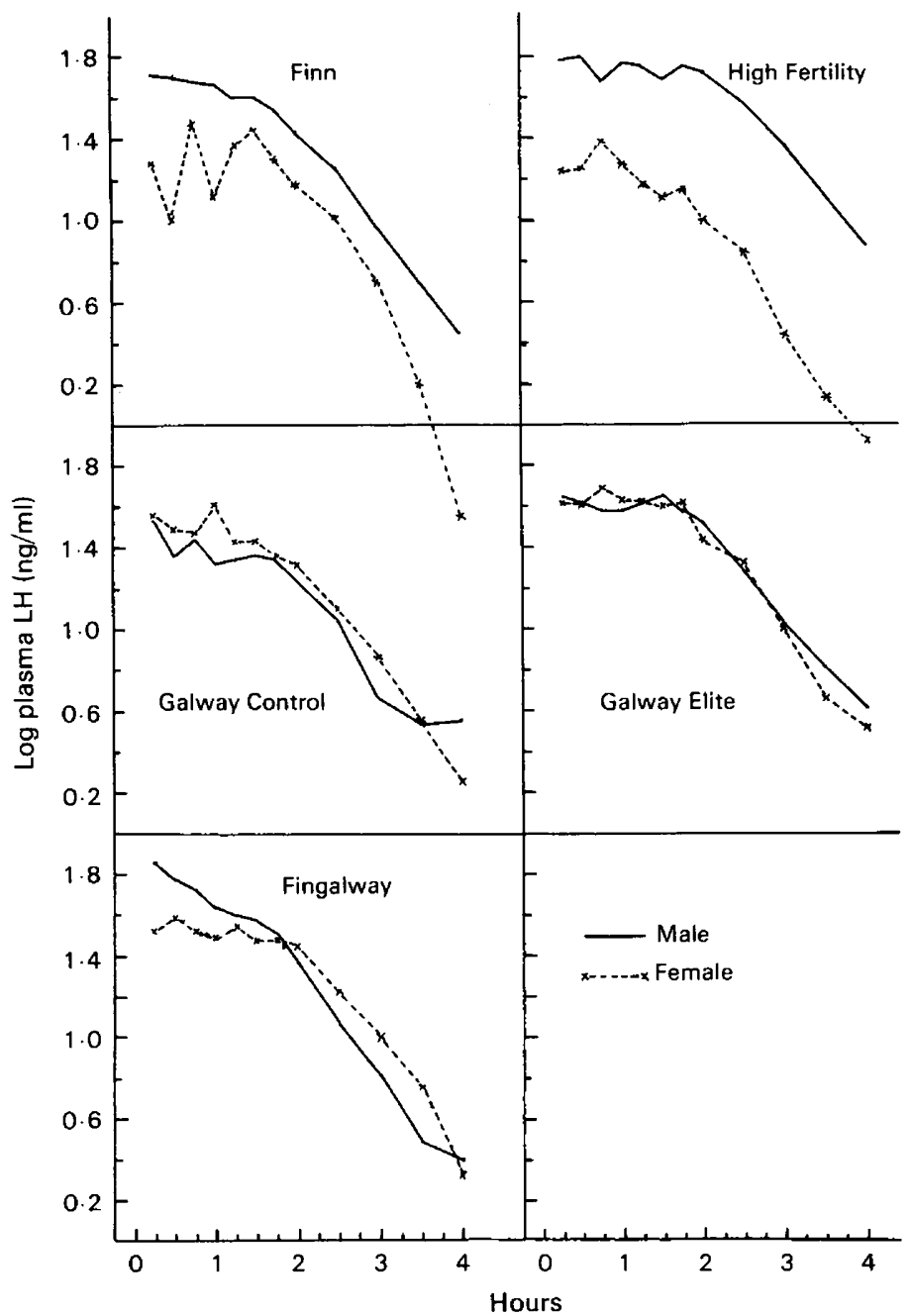

Text-fig. 3. Sex differences in plasma LH, after an injection of $100 \mu \mathrm{g} \mathrm{GnRH}$, in 8-week-old lambs from five genetic groups. The number of lambs per sex $x$ genetic group subclass varied from 3 to 6 .

Table 3 is to state that breed differences were evident for females but not for male lambs. Because there was little evidence for sex differences in the two Galway groups the effect of selection for high litter size (Galway Elite) on response to GnRH was estimated by comparing Galway Control and Galway Elite lambs for the sexes combined. Selection increased all variables, with the $t$ test approaching significance at the $5 \%$ level for Total LH $(t=1 \cdot 84$, $P<0.07)$.

The least squares mean for $4 \mathrm{~S}-\mathrm{LH}$ was 1.56 with a standard deviation of 0.187 which yields a coefficient of variation of $12 \%$. The corresponding values for plasma $\mathrm{LH}$ before injection were $0.51,0.340$ and $78 \%$, respectively (Hanrahan et al., 1977).

\section{Discussion}

It is clear from the present results that the age of male lambs has a major influence on the response, in terms of plasma $\mathrm{LH}$ concentrations, to $\mathrm{GnRH}$ administration. This agrees with the 
findings of Galloway \& Pelletier (1974) for lambs within the age range of those studied in the present work. Lee et al. (1976), using GnRH infusion, also obtained large increases in the LH response between 4 and 8 weeks of age. The observed increases are consistent with the rapid increase in pituitary LH content found during this stage of development (Skinner, Booth, Rowson \& Karg, 1968; Courot, de Reviers \& Pelletier, 1975) and the results of Jenkin, Heap \& Symons (1977) demonstrating a high correlation between pituitary LH content and plasma LH levels following GnRH administration.

The absence of an interaction between age and breed indicates that the age-related changes were the same for all the breeds studied. The results also show that the age effects are not dependent on the amount of GnRH given. The increased response with age was such that levels found in 8-week-old lambs $120 \mathrm{~min}$ after injection were generally higher than the 15 -min levels for 4-week-old lambs. The values for Slope-LH (Table 2) show that the rate of decline of plasma LH during the period after injection was much lower in the older animals. It was evident from inspection of sequential levels in individuals that at 4 weeks of age the plasma LH declined continuously from the 15-min level whereas the pattern in individual 8-week-old lambs often revealed non-decreasing plasma $\mathrm{LH}$ for the first three sampling times.

Both experiments agree in finding no differences among Finn, Fingalway and High Fertility males in their response to GnRH. The only significant effect in Exp. 2 was the breed $\times$ sex interaction for all the derived indices of plasma LH concentration. Inspection of Table 3 clearly indicates that the reason for this interaction is the similarity of all breed means for the male lambs whereas substantial differences among breeds are evident for the females. A lower response to $\mathrm{GnRH}$ by female lambs of the Finn breed has been reported by Carr, Land \& Sales (1976). The observed sex differences contrast with the conclusion that sex and breed $x$ sex effects were absent in our study of basal levels at 8 weeks of age (Hanrahan et al., 1977). However, the much larger coefficient of variation in basal levels (78\%) compared with levels after GnRH treatment (12\%) could account for the failure to detect a significant breed $\times$ sex interaction in the basal levels. The within-subclass correlation between average LH level before GnRH injection and Total-LH was $0.33(P<0.10)$, which is not indicative of a close relationship between basal levels of plasma $\mathrm{LH}$ and response to GnRH. However, a higher correlation might possibly be obtained if a GnRH dose closer to physiological levels was employed. The breed differences among female lambs may reflect breed variation in the rate of development of the hypothalamic-pituitary-ovarian circuit with respect to its response to ovarian steroids, since this control mechanism appears to come into operation around 8 weeks of age (Foster et al., 1975). The setting of the level of sensitivity of the circuit to ovarian steroids could also be the basis of breed differences. This interpretation is suggested by the observations of Land \& Carr (1975) and Land (1976) which point to a lowered sensitivity to the negative feedback effects of steroids in the Finn breed.

The present results have not shown any consistent breed differences in plasma $\mathrm{LH}$ levels of male lambs following GnRH injection despite large differences in fecundity among the breeds studied. This result appears to conflict with the findings of Carr et al. (1976). It is, however, consistent with our previous results for basal LH levels at 4 and 8 weeks of age in the same breeds (Hanrahan et al., 1977). Bindon et al. (1974) also failed to find an association between breed fecundity and plasma $\mathrm{LH}$ in male lambs following GnRH injection. The suggestion of a greater response to $\mathrm{GnRH}$ by Galway Elite lambs tends to support our previous finding that selection for increased litter size was associated with increased basal LH levels at 8 weeks of age (Hanrahan et al., 1977) despite the low correlation estimate for these two variables.

The present results indicate that gonadotrophin-releasing hormones are a useful tool in overcoming the inherent variation of tonic plasma LH levels, although a better understanding of the dynamics of pituitary and plasma LH in relation to age and sex will be necessary before $\mathrm{LH}$ measurements are likely to become useful as an aid to genetic selection for changes in fecundity. 
We thank Mrs K. Horan and P. O'Dea, T. Lally, G. McLoughlin and R. Triggs for their technical assistance and NIAMDD, Bethesda, Maryland, U.S.A., for the supply of purified ovine LH.

\section{References}

Bindon, B.M. (1973) Genetic differences in plasma luteinizing hormone of the prepubertal lamb. $J$. Reprod. Fert. 32, 347-348.

Bindon, B.M., Ch'ang, T.S. \& Evans, R. (1974) Genetic effects on $\mathbf{L H}$ release by oestradiol and gonadotrophin-releasing hormone in prepubertal lambs. J. Reprod. Fert. 36, 477, Abstr.

Carr, W.R. \& Land, R.B. (1975) Plasma luteinizing hormone levels and testis diameters of ram lambs of different breeds. J. Reprod. Fert. 42, 325-333.

Carr, W.R., Land. R.B. \& Sales, D.I. (1976) The effect of gonadotrophin releasing hormone (GnRH) on plasma levels of luteinizing hormone $(\mathrm{LH})$ in lambs of breeds with high and low ovulation rates. Annls Biol. anim. Biochim. Biophys. 16, 167, Abstr.

Courot, M., de Reviers, M.M. \& Pelletier, J. (1975) Variations in pituitary and blood LH during puberty in the male lamb. Relation to time of birth. Annls Biol. anim. Biochim. Biophys. 15, 509-516.

Foster, D.L., Jaffe, R.B. \& Niswender, G.D. (1975) Sequential patterns of circulating $\mathrm{LH}$ and FSH in female sheep during the early postnatal period: effect of gonadectomy. Endocrinology 96, 15-22.

Galloway, D.G. \& Pelletier, J. (1974) Infiuence of age on the pituitary response of male lambs to synthetic LH-RH injection. Horm. Metab. Res. 6, 240-241.

Hanrahan, J.P., Quirke, J.F. \& Gosling, J.P. (1977) Genetic and non-genetic effects on plasma $\mathrm{LH}$ concentrations in lambs at 4 and 8 weeks of age. $J$. Reprod. Fert. 51, 343-349.

Jenkin, G., Heap, R.B. \& Symons, D.B.A. (1977) Pituitary responsiveness to synthetic LH-RH and pituitary $\mathrm{LH}$ content at various reproductive stages in sheep. J. Reprod. Fert. 49, 207-214.

Land, R.B. (1976) The sensitivity of the ovulation rate of Finnish Landrace and Blackface ewes to exogenous oestrogen. J. Reprod. Fert. 48, 217-218.

Land, R.B. \& Carr, W.R. (1975) Testis growth and plasma LH concentration following hemicastration and its relation with female prolificacy in sheep. $J$. Reprod. Fert. 45, 495-501.

Lee, V.W.K., Cumming, I.A, de Kretser, D.M., Findlay, J.K., Hudson, B. \& Keogh, E.J. (1976) Regulation of gonadotrophin secretion in rams from birth to sexual maturity. II. Response of the pituitary-testicular axis to LH-RH infusion. J. Reprod. Fert. 46, 7-11.

Skinner, J.D., Booth, W.D., Rowson, L.E.A. \& Karg, H. (1968) The post-natal development of the reproductive tract of the Suffolk ram, and changes in the gonadotrophin content of the pituitary. J. Reprod. Fert. 16, 463-477.

Thimonier, J., Pelletier, J. \& Land, R.B. (1973) The concentration of plasma $\mathrm{LH}$ in male and female lambs of high and low prolificacy breed types. $J$. Reprod. Fert. 31, 498-499.

Received 11 February 1980 